\title{
The Long-term Effect of Standardized Anal Dilatation for Chronic Anal Fissure on Anal Continence
}

\author{
Ilia Pinsk ${ }^{1}$, David Czeiger ${ }^{2}$, Daria Lichtman ${ }^{1}$, Avraham Reshef $^{1}$ \\ ${ }^{1}$ Unit of Colorectal Surgery, ${ }^{2}$ Department of General Surgery, Soroka University Medical Center, Beer-Sheva, Israel
}

Purpose: For the past several decades, internal anal sphincterotomy has generally been considered to be the standard operation for an anal fissure. However, wound complications inherent in this operation forced surgeons to look for an alternative form of treatment. The aim of our study was to evaluate the long-term outcome of anal dilatation for chronic anal fissure, especially possible negative impact on anal sphincter function.

Methods: The study was approved by the local Institutional Review Board and given a waiver of written consent. A phone call survey was undertaken among a group of consecutive patients who had an anal dilatation by standardized technique for chronic anal fissure for the period between 2000 and 2016. The survey included medical, obstetrical and surgical-related data, Wexner fecal incontinence score, recurrence of the anal fissure, and the need for additional medical intervention. Five hundred 48 patients were identified after limitations of age, concomitant pathology, and procedures that were applied to the hospital computerized database. Eighty-five patients (group A) agreed to participate in the survey and 463 patients did not.

Results: There were no differences between groups in demographic information and medical records data; therefore, group A may well represent a satisfactory sample of the whole group. The interval between the procedure and the survey was $6.8 \pm 2.7$ years. The Wexner incontinence score was 0 in $94 \%$ of patients.

Conclusion: Anal dilatation, performed in a systematic and standardized way, has a successful outcome with no complications and has no clear long-term negative impact on anal sphincter function.

\section{Keywords: Anal dilatation; Complications; Fissure in ano; Incontinence}

\section{INTRODUCTION}

Hypertonicity of internal anal sphincter has been recognized as a common and classic finding on the digital rectal examination of patients suffering from anal fissure and has been documented by manometry. In spite of being an old problem, the exact mechanism of development of anal fissure and cause-effect relations between the fissure and hypertonic internal sphincter remain uncer-

Received: Apr 30, 2019 - Revised: Mar 8, 2020 - Accepted: Mar 16, 2020 Correspondence to: Ilia Pinsk, M.D.

Unit of Colorectal Surgery, Soroka University Medical Center, Yitzhack I.

Rager Blvd 151, Beer-Sheva, Israel

E-mail: iliapi@clalit.org.il

ORCID: https://orcid.org/0000-0002-2628-5855

(C) 2021 The Korean Society of Coloproctology

This is an open-access article distributed under the terms of the Creative Commons Attribution NonCommercial License (https://creativecommons.org/licenses/by-nc/4.0) which permits unrestricted non-

commercial use, distribution, and reproduction in any medium, provided the original work is properly cited. tain. The history of changes in operative approach to anal fissures has known different strategies of altering this physiologic dysfunction, which are described in classic textbooks of colon and rectal surgery and Standard Practice Task Force of the American Society of Colon and Rectal Surgeons, as well as of other national societies $[1,2]$. The finger sphincter stretching, as the first-line recommended surgical procedure in the 1960s, lost its popularity. Lateral internal sphincterotomy became the preferred method in mid-1970s [1] due to its more accurate, measurable, less traumatic, and probably more successful outcome compared to anal dilatation. Since the 1980s, lateral internal sphincterotomy is considered to be the standard operation. Later, this recommendation was emphasized by a statement that "stretch should probably be abandoned in favor of partial internal sphincterotomy until a better operation is described" [3]. It was an absolute disqualification of manual anal dilatation, as risks to continence were clear. It had been estimated that the risk for temporary incontinence reaches $30 \%[4]$ and of permanent fecal incontinence up to $10 \%$ [5]. 


\section{Coloproctology lia Pinsk, et al}

The change in practice was extensively studied and represented in recent reviews and meta-analyses. It has been confirmed that manual anal stretch had higher rate of incontinence and was not more effective than internal sphincterotomy [6-8]. Nevertheless, lateral internal sphincterotomy, being claimed for several decades to be the gold standard therapy for chronic anal fissure, has its own wound-related complications including fistula, bleeding, abscess, or non-healing wound in up to $3 \%$ of patients $[9,10]$. These complications are not known in the practice of anal dilatation [1114]. Recently, less traumatic, precise, measurable, and reproducible techniques of anal dilatation were designed and introduced into practice under different names; staged, gradual, and balloon dilation [11-16].

For more than 25 years the standard policy of surgical treatment of chronic anal fissure in our colorectal unit has been hydropneumatic balloon anal dilatation that at some point had been replaced with use of dilators (Sohn's dilators) in a standardized fashion and in this way abolishing the well-known high risk of permanent sphincter damage from vigorous finger stretch from the one side and possible septic complications of sphincterotomy from another. Focusing on fecal continence as the main issue of surgical treatment of chronic anal fissure we present herein the long-term follow-up of our patients treated by this method between 2000 and 2016.

\section{METHODS}

The study was approved by the Institutional Review Board of Soroka University Medical Center and given a waiver of written consent. The hospital computerized database has been searched for anal dilatation procedure for the period from January 1, 2000 to December 31, 2016. Total of 1,536 patients who had anal dilatation were identified.

To be focused on the standardized procedure and to eliminate concomitant operations for other pathology than anal fissure, such as hemorrhoids, fistulas etc., we limited our database exclusively to procedures performed on elective basis, in patients between 18 and 60 years old, and only for anal fissure pathology, excluding also patients with Crohn disease. The upper limit of age was set up in view of a possible concomitant impairment of anal sphincter function related to aging. These limitations have reduced the original number of patients from 1,536 to 548. This pooled computerized data included demographic information (age at the time of the procedure, sex, and ethnicity), phone contact, comorbidities, pre- and postprocedural interventions, and follow-up at the coloproctology unit.

The phone call questionnaire was set up and approved by the local institutional board and started from the introduction of the aim of the study and requesting for agreement to continue with the interview. The survey included medical, obstetrical, and surgical-related data that can be missing in our computerized database, the Wexner fecal incontinence score, recurrence of the anal fissure, and the need for additional medical or/and surgical intervention. At the end of the phone call interview, every patient was invited to visit our proctology clinic to discuss any related issues.

\section{Statistics}

The database was created using the Excel program of Microsoft Office (Microsoft, Redmond, WA, USA). Statistical analysis was performed with GraphPad Prism software (GraphPad Software, San Diego, CA, USA). Statistically significant differences between means of the 2 groups were tested by using the $t$-test or the nonparametric Mann-Whitney test for continuous variables (2-tailed). Results are presented as mean \pm standard deviation. Categorical variables are presented as percentages and analyzed by Fisher exact test (2-tailed). Significance was considered at $\mathrm{P} \leq 0.05$.

\section{RESULTS}

Eighty-five out of the 548 patients (15.5\%) have been found and reached by phone call and agreed to participate in the survey. The demographic data for the surveyed group (group A, 85 patients) and non-responders (group B, 463 patients) are presented in Table 1. Age at survey and sex ratios of patients in groups $A$ and $B$ were the same $(\mathrm{P}=0.29$ and $\mathrm{P}=0.9$, respectively). The length of follow-up was the same as well. All patients were discharged on the same day and there were no readmissions or recorded complications on follow-up visits in our proctology clinic.

According to medical records, a repeated surgery was needed in 23 of 548 patients (4.2\%); 7 patients (8\%) in group A and 16 patients $(3.5 \%)$ in group $\mathrm{B}$. The mean time between interventions was $5.7 \pm 3.7$ years in group $A$ and $2.3 \pm 2.3$ years in group $B(P=0.01)$. The mean interval between the procedure and the phone call questionnaire was significantly different between the groups; $6.8 \pm 2.7$ years in group $A$ and $10.7 \pm 3.5$ years in group $\mathrm{B}(\mathrm{P}<0.0001)$.

Table 2 represents the data from the phone survey. In group A, $76.5 \%$ of patients were treated by stool softeners and nifedipine gel $0.2 \%$ before surgery. Twenty-eight patients $(32.9 \%)$ recalled recurrence of complaints, yet only 13 patients $(15.3 \%)$ were sure that the recurrent fissure was diagnosed, and, as shown in Table 1,

Table 1. Demographic and follow-up data from computerized database

\begin{tabular}{lccc}
\hline Variable & $\begin{array}{c}\text { Group A } \\
(\mathrm{n}=85)\end{array}$ & $\begin{array}{c}\text { Group B } \\
(\mathrm{n}=463)\end{array}$ & P-value \\
\hline Age at survey (yr) & $48.7 \pm 12.9$ & $47.2 \pm 12.4$ & 0.290 \\
Sex (\%), male:female & $55.3: 44.7$ & $56.6: 43.4$ & 0.900 \\
Length of follow-up ${ }^{\mathrm{a}}(\mathrm{yr})$ & $6.8 \pm 2.7$ & $10.7 \pm 3.5$ & $<0.001$ \\
Second surgery & $7(8.2)$ & $16(3.5)$ & \\
Time between procedures (yr) & $5.2(2-10)$ & $2.3(0.33-9.7)$ &
\end{tabular}

Values are presented as mean \pm standard deviation, percent only, number (\%), or median (range).

alnterval between the procedure and the phone call questionnaire. 
Table 2. Follow-up data from the questionnaire survey

\begin{tabular}{lc}
\hline Variable & Group A $(\mathrm{n}=85)$ \\
\hline Preoperative treatment & $65(76.5)$ \\
Recurrence of complains & $28(32.9)$ \\
Recurrent fissure & $13(15.3)$ \\
Time to recurrence $(\mathrm{mo})$ & $12(2-49)$ \\
Wexner incontinence score $>0$ & $5(5.9)$ \\
\hline
\end{tabular}

Values are presented as number (\%) or median (range).

only 7 patients $(8.2 \%)$ had a repeated anal dilatation. The mean time to recurrence of complaints was 12 months. In the female group, 27 out of 36 patients (75.0\%) had vaginal delivery at some point before the anal fissure issues. Thirteen patients $(36.1 \%)$ had 3 and more vaginal deliveries, and 20 patients (55.6\%) had some degree of tear. The Wexner incontinence score in 80 patients (94.1\%) was 0 . Five patients ( 3 males and 2 females) had 3 or more points (Table 2).

Each interviewed patient was welcomed to come to the colorectal clinic for the evaluation of any old or new complains that could be related to anal fissure or to the procedure, but no one used this offer.

\section{DISCUSSION}

In our experience, standardized anal dilatation is a reliable and well-established technique. The balloon technique was used in our colorectal unit since 1992 with results reported by Walfisch and Silberstein [12]. Looking into outcomes of 175 patients treated by balloon anal dilatation and 100 patients who underwent lateral internal sphincterotomy, they concluded that success in healing anal fissure is compatible to that of sphincterotomy, but in contrast to the rate of wound complication of $4 \%$ and anal incontinence of $2 \%$ in the sphincterotomy group, these rates were zero in the group of balloon anal dilatation. Because of financial reasons in 1999, we switched our practice to using 3-sized Sohn's dilatators: 30, 35, and $40 \mathrm{~mm}$ [13], and we have been using this set until now. The long-term results of our study have shown no complications, $4.2 \%$ rate of a surgical reintervention, and $5.8 \%$ of reporting of more than 0 points on the Wexner incontinence score.

Procedural outcome of anal dilatation with respect to possible anatomic and functional damage to anal sphincters was in the scope of many studies. Sohn et al. [13] showed 3-month healing rate of $94 \%$ and $100 \%$ pain relief within 12 hours with no complications reported.

Renzi et al. [17] prospectively evaluate the clinical, anatomic, and functional pattern in patients treated by pneumatic balloon dilation using anal manometry and ultrasonography. It seems to be an effective, safe, and easy procedure that decreases anal resting pressure without significant endosonographically detectable sphincter damage. In another study published in 2008, Renzi et al. [14] show that like the lateral internal sphincterotomy, pneumatic balloon dilatation grants a high anal fissure-healing rate, but with a statistically significant reduction in postoperative anal incontinence.

We believe that, being the only center in our district, we have a minimal, if any, loss of our patients from follow-up. Therefore, as the first step, we decided to review our patients by phone based on the questionnaire to understand the level of satisfaction and the percentage of possible significant permanent incontinence that is the main issue that triggered to exclude anal dilatation from surgical practice. We did not investigate the anatomical and functional disturbances of anal sphincter in our series because there were no alarming complaints from our patients during follow-up to justify such an expensive investigation. In addition, in our opinion, there is no need to repeat substantial studies that already showed that anal dilatation up to diameter of $4 \mathrm{~cm}$ even by rectoscope used during the knowingly prolonged transanal endoscopic microsurgery does not cause significant long-term functional harm to the anal sphincter $[18,19]$.

The overall rate of any incontinence during long-term follow-up in our study is $6 \%$. Looking into the details, this number does not differ significantly from continence rates in the general population. The estimated prevalence of fecal incontinence among community-dwelling adults has varied from $0.4 \%$ to $18 \%$ [20]. In a meta-regression analysis from Pretlove et al. [21] including 29 studies, the overall average rate of solid and liquid anal incontinence was $4.3 \%$. The rates were similar in men and women among younger participants, being on average $0.8 \%$ in men and $1.6 \%$ in women. However, in those aged over 60 years, rates were on average $5.1 \%$ in men and $6.2 \%$ in women. This data was the reason to limit the age of inclusion criteria in our study to 60 years. Previous studies have shown lower overall prevalence rates. Nelson et al. [22] found a 2.2\% anal incontinence rate in a NorthAmerican population, whereas the group of Perry et al. [23] showed monthly or more leakage in $3.3 \%$ and soiling in $2.7 \%$ of adult subjects. In a Swedish study by Walter et al. [24], leakage of feces more than once a month in the case of loose stools was $10 \%$ and for solid feces $1.4 \%$ and $0.4 \%$ for women and men respectively. Melville et al. [25] investigated the prevalence of fecal incontinence in United States women. They found that the prevalence of fecal incontinence increased markedly with age; from $4 \%$ in age group of $30-39$ years to $7 \%$ in age group of $50-59$ years, $12 \%$ in age group of $60-69$ years and up to $15 \%$ in the age group of 80-89 years. Another population-based age-stratified study by Aitola et al. [26] has shown that $3.3 \%$ of population at age of 30 to 39 years report on fecal incontinence occurring at least twice a month within the last year, compared to $5.6 \%$ in age group of 50 to 59 years. In addition, they found that urinary incontinence, anal fistula surgery, and hemorrhoidectomy seemed to be significantly associated with fecal incontinence (odds ratio, 5.38, 2.43, and 1.88 , respectively). 
A late impact of standardized anal dilatation on anal continence in aging patients is not as clear as other comorbidities mentioned above. In our study, $6 \%$ of responders reported fecal incontinence score of more than zero. The worst score of 16 was obtained from a woman aged 51 years, who had intervention at age 43 years with the history of 3 previous vaginal deliveries, obstetric tear, body mass index (BMI) $>30 \mathrm{~kg} / \mathrm{m}^{2}$ and fibromyalgia. The score of 8 was reported by a male patient who had hemorrhoidectomy surgery 4 months before the anal fissure problem. The score of 6 was reported by a 48 -year-old healthy man 2 years after anal dilatation. Another patient with 5 points of score was a 41-year-old overweight $\left(\mathrm{BMI},>30 \mathrm{~kg} / \mathrm{m}^{2}\right)$ diabetic female. She is a heavy smoker, had 1 vaginal delivery with no tear, and she had anal dilatation twice at age 30 and 35 years. The last male patient who had scored 3 points is 40 years old at survey, and had surgery for perianal abscess 2 years before anal fissure treatment.

The inability to contact most of the patients is a potential source of bias. Sample of 85 out of 548 patients is a satisfactory sample leaving only $10 \%$ margin of error with confidence level of $95 \%$. As it is shown in Table 1, there was not a significant difference in age and sex between responders and those who could not be reached, so it might be expected that the responding patients were reasonably representative of the whole group. In addition, patients have ongoing contact with the public health and hospital system and thus through the common computerized files their continuing proctological problems would have been recognized.

Despite the statistical limitation of this study, it represents a long-term assessment of a huge anal fissure workload over 15 years for a single university colorectal unit. We were not able to identify a single patient who had significant incontinence that could be attributed to sphincter damage caused by anal dilatation. All contacted patients were invited to schedule an appointment at the colorectal clinic, but even those 5 patients who had fecal incontinence refused this offer. Moreover, those patients who respond to the survey would have tended to skew the outcomes toward a poorer result, as this phenomenon is a well-known questionnaire bias.

Little data is available regarding the long-term follow-up after lateral internal sphincterotomy. The longest follow-up of 4.3 years we have found described by Walker et al. [10] in 1985 reported an incidence of persistent minor defects in anal continence of $15 \%$. Usatoff and Polgase [27] found that $18 \%$ of patients had new constant minor weakening of anal control after a mean follow-up of 41 months. Although the procedure of lateral internal sphincterotomy is widely accepted as the gold standard approach for anal fissure, it is not perfect in the long run in terms of continence. In addition to late imperfection of anal function that could be related to aging and other risk factors, the lateral internal sphincterotomy has its own low but not negligible rate of up to $4 \%$ of septic or wound-related complications (postoperative cellulitis, bleeding/ hematoma, abscess formation, and wound infection) requiring additional interventions, and up to $18 \%$ of urine retention de- manding catheterization [28-30].

In conclusion, anal dilatation by standard-sized dilators is a simple, reliable, consistent, less traumatic, reproducible, nonoperator depended, and cheap intervention for treatment of anal fissure and has the comparable beneficial effects of sphincterotomy on anal fissure without the need for any incision, thereby minimizing the risk of complications. This standardized intervention has no harm to future anal sphincter function.

\section{REFERENCES}

1. Goligher JC, Duthie HL, Nixon HH. Surgery of the anus, rectum and colon. 3rd ed. Springfield (IL): Thomas; 1975.

2. Stewart DB Sr, Gaertner W, Glasgow S, Migaly J, Feingold D, Steele SR. Clinical practice guideline for the management of anal fissures. Dis Colon Rectum 2017;60:7-14.

3. Nelson RL. Treatment of anal fissure. BMJ 2003;327:354-5.

4. Watts JM, Bennett RC, Goligher JC. Stretching of anal sphincters in treatment of fissure-in-ano. Br Med J 1964;2:342-3.

5. Nielsen MB, Rasmussen OO, Pedersen JF, Christiansen J. Risk of sphincter damage and anal incontinence after anal dilatation for fissure-in-ano: an endosonographic study. Dis Colon Rectum 1993;36:677-80.

6. Nelson RL, Chattopadhyay A, Brooks W, Platt I, Paavana T, Earl S. Operative procedures for fissure in ano. Cochrane Database Syst Rev 2011;2011:CD002199.

7. Nelson RL, Manuel D, Gumienny C, Spencer B, Patel K, Schmitt K, et al. A systematic review and meta-analysis of the treatment of anal fissure. Tech Coloproctol 2017;21:605-25.

8. Ebinger SM, Hardt J, Warschkow R, Schmied BM, Herold A, Post $S$, et al. Operative and medical treatment of chronic anal fissuresa review and network meta-analysis of randomized controlled trials. J Gastroenterol 2017;52:663-76.

9. Gordon PH, Vasilevsky CA. Symposium on outpatient anorectal procedures: lateral internal sphincterotomy: rationale, technique and anesthesia. Can J Surg 1985;28:228-30.

10. Walker WA, Rothenberger DA, Goldberg SM. Morbidity of internal sphincterotomy for anal fissure and stenosis. Dis Colon Rectum 1985;28:832-5.

11. Yucel T, Gonullu D, Oncu M, Koksoy FN, Ozkan SG, Aycan O. Comparison of controlled-intermittent anal dilatation and lateral internal sphincterotomy in the treatment of chronic anal fissures: a prospective, randomized study. Int J Surg 2009;7:228-31.

12. Walfisch S, Silberstein E. Balloon anal dilatation for anal fissure. Tech Coloproctol 1998;2:73-5.

13. Sohn N, Eisenberg MM, Weinstein MA, Lugo RN, Ader J. Precise anorectal sphincter dilatation: its role in the therapy of anal fissures. Dis Colon Rectum 1992;35:322-7.

14. Renzi A, Izzo D, Di Sarno G, Talento P, Torelli F, Izzo G, et al. Clinical, manometric, and ultrasonographic results of pneumatic balloon dilatation vs. lateral internal sphincterotomy for chronic anal fissure: a prospective, randomized, controlled trial. Dis Co- 
lon Rectum 2008;51:121-7.

15. Gaj F, Biviano I, Candeloro L. Low energy manual anal stretch: an approach in the treatment of chronic anal fissure. Minerva Chir 2017;72:103-7.

16. Boschetto S, Giovannone M, Tosoni M, Barberani F. Hydropneumatic anal dilation in conservative treatment of chronic anal fissure: clinical outcomes and randomized comparison with topical nitroglycerin. Tech Coloproctol 2004;8:89-92.

17. Renzi A, Brusciano L, Pescatori M, Izzo D, Napolitano V, Rossetti $\mathrm{G}$, et al. Pneumatic balloon dilatation for chronic anal fissure: a prospective, clinical, endosonographic, and manometric study. Dis Colon Rectum 2005;48:121-6.

18. Mora López L, Serra Aracil X, Hermoso Bosch J, Rebasa P, Navarro Soto S. Study of anorectal function after transanal endoscopic surgery. Int J Surg 2015;13:142-7.

19. Hompes R, Ashraf SQ, Gosselink MP, van Dongen KW, Mortensen NJ, Lindsey I, et al. Evaluation of quality of life and function at 1 year after transanal endoscopic microsurgery. Colorectal Dis 2015;17:054-61.

20. Macmillan AK, Merrie AE, Marshall RJ, Parry BR. The prevalence of fecal incontinence in community-dwelling adults: a systematic review of the literature. Dis Colon Rectum 2004;47:1341-9.

21. Pretlove SJ, Radley S, Toozs-Hobson PM, Thompson PJ, Coomarasamy A, Khan KS. Prevalence of anal incontinence according to age and gender: a systematic review and meta-regression analysis. Int Urogynecol J Pelvic Floor Dysfunct 2006;17:407-17.

22. Nelson R, Norton N, Cautley E, Furner S. Community-based prevalence of anal incontinence. JAMA 1995;274:559-61.
23. Perry S, Shaw C, McGrother C, Matthews RJ, Assassa RP, Dallosso $\mathrm{H}$, et al. Prevalence of faecal incontinence in adults aged 40 years or more living in the community. Gut 2002;50:480-4.

24. Walter S, Hallböök O, Gotthard R, Bergmark M, Sjödahl R. A population-based study on bowel habits in a Swedish community: prevalence of faecal incontinence and constipation. Scand J Gastroenterol 2002;37:911-6.

25. Melville JL, Fan MY, Newton K, Fenner D. Fecal incontinence in US women: a population-based study. Am J Obstet Gynecol 2005; 193:2071-6.

26. Aitola P, Lehto K, Fonsell R, Huhtala H. Prevalence of faecal incontinence in adults aged 30 years or more in general population. Colorectal Dis 2010;12:687-91.

27. Usatoff V, Polglase AL. The longer term results of internal anal sphincterotomy for anal fissure. Aust N Z J Surg 1995;65:576-8.

28. Ortiz H, Marzo J, Armendariz P, De Miguel M. Quality of life assessment in patients with chronic anal fissure after lateral internal sphincterotomy. Br J Surg 2005;92:881-5.

29. Menteş BB, Tezcaner T, Yilmaz U, Leventoğlu S, Oguz M. Results of lateral internal sphincterotomy for chronic anal fissure with particular reference to quality of life. Dis Colon Rectum 2006;49: 1045-51.

30. Kiyak G, Korukluoğlu B, Kuşdemir A, Sişman IC, Ergül E. Results of lateral internal sphincterotomy with open technique for chronic anal fissure: evaluation of complications, symptom relief, and incontinence with long-term follow-up. Dig Dis Sci 2009;54: 2220-4. 